Article

\title{
Structural Requirements for Antimicrobial Activity of Phenolic Nor-Triterpenes from Celastraceae Species
}

\author{
Laila Moujir ${ }^{1}$, Manuel R. López ${ }^{1}$, Carolina P. Reyes ${ }^{2}$, Ignacio A. Jiménez ${ }^{2}$ and \\ Isabel L. Bazzocchi ${ }^{2, *(D)}$ \\ 1 Departamento de Bioquímica, Microbiología, Biología Celular y Genética, Facultad de Farmacia, \\ Universidad de La Laguna, 38206 La Laguna, Tenerife, Spain \\ 2 Instituto Universitario de Bio-Orgánica Antonio González, Departamento de Química Orgánica, \\ Universidad de La Laguna, Avda. Astrofísico Francisco Sánchez 2, 38206 La Laguna, Tenerife, Spain \\ * Correspondence: ilopez@ull.es; Tel.: +34-922-318576
}

Received: 27 June 2019; Accepted: 19 July 2019; Published: 24 July 2019

check for updates

Featured Application: Identifying the structural requirements of phenolic nor-triterpene framework as potential antimicrobial agents.

\begin{abstract}
The emergence of pathogenic bacteria-resistant strains is a major public health issue. In this regard, natural product scaffolds offer a promising source of new antimicrobial drugs. In the present study, we report the antimicrobial activity against Gram-positive and Gram-negative bacteria and the yeast Candida albicans of five phenolic nor-triterpenes (1-5) isolated from Maytenus blepharodes and Maytenus canariensis in addition to four derivatives (6-9), three of them reported for the first time. Their stereostructures have been elucidated on the basis of spectroscopic analysis, including one-dimensional (1D) and two-dimensional (2D) NMR techniques, spectrometric methods, and comparison with data reported in the literature. To understand the structural basis for the antimicrobial activity of this type of compounds, we have performed an in-depth study of the structure-activity relationship (SAR) of a series of previously reported phenolic nor-triterpenes. The SAR analysis was based on the skeleton framework, oxidation degree, functional groups, and regiosubstitution patterns, revealing that these aspects modulate the antimicrobial activity.
\end{abstract}

Keywords: Maytenus; celastroloids; semisynthesis; antibacterial activity; structure-activity relationship

\section{Introduction}

The resistance of common pathogens to standard antibiotic therapies is rapidly becoming a major public health problem all over the world [1], and consequently, there is a need to develop new structural and mechanistic classes of antibiotic agents. In this regard, the development of new antibiotics inspired in natural product scaffolds seems the best short-term solution to address antibiotic resistance [2].

The Celastraceae family is distributed mainly in tropical and subtropical regions of the world including North Africa, South America, and East Asia, and their species have a long history in traditional medicine [3]. The most representative genus in this family is Maytenus, with more than 225 species [4]. In the Amazonian region, species of this genus are well known for their use in the treatment of rheumatism, gastrointestinal diseases, and as an antitumoral for skin cancer [4]. The therapeutic potential of Maytenus species has been mainly attributed to celastroloids, chemotaxonomic markers of the family [5]. The term celastroloid refers to methylenequinone nor-triterpenes with a 24-nor- $D: A$-friedo-oleanane skeleton. Celastrol [6] and pristimerin [7] are the first and most frequently reported celastroloids, and later on, this term was extended to related phenolic nor-triterpenes [5,8] and their dimer and trimer congeners [9]. This particular class of natural 
products shows a wide range of bioactivities, including cytotoxic [10,11], anti-inflammatory [12], antioxidant [13], antiparasitic [14], and insecticidal [15] properties. Concerning their antimicrobial activity, pristimerin, tingenone, celastrol, and netzahualcoyone (Figure 1) exhibit inhibitory activity against Gram-positive bacteria $[8,16,17]$, and the mode of action of netzahualcoyone against Bacillus subtilis and Escherichia coli has been investigated [18,19]. Regarding the phenolic nor-triterpenes, studies on their antimicrobial activity, mechanism of action against Gram-positive bacteria, and preliminary structure-activity relationship have been reported [20-25].

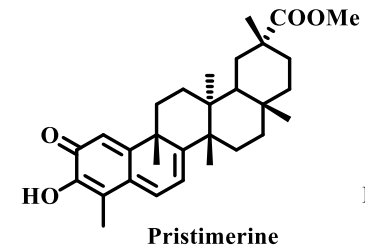

Pristimerine
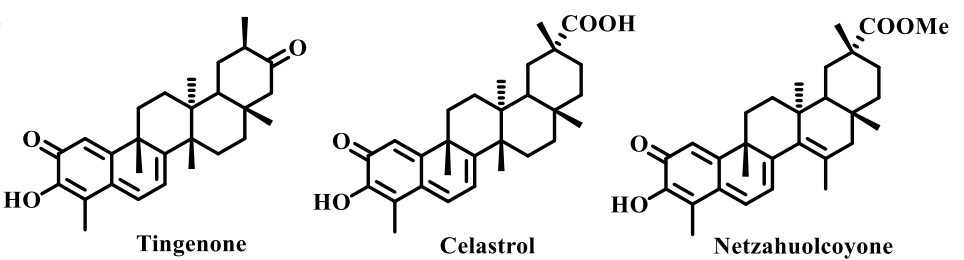

Figure 1. Most frequently reported antimicrobial celastroloids from Celastraceae species.

As part of an intensive investigation into antimicrobial metabolites from Celastraceae species, we report herein on the minimal inhibitory concentrations (MICs) of five natural phenolic nor-triterpenes (1-5) and four derivatives (6-9), three of them reported for the first time, against Gram-positive and Gram-negative bacteria, and the yeast Candida albicans. The structure-activity relationship study of compounds 1-9 was expanded by the known antimicrobial activity of a series of phenolic nor-triterpenes (10-26), previously reported by our research group [20-23,25], to deepen our knowledge of the structural requirements for their activity.

\section{Materials and Methods}

\subsection{General Procedures}

Optical rotations were measured on a Perkin Elmer 241 automatic polarimeter in $\mathrm{CHCl}_{3}$ at $25^{\circ} \mathrm{C}$, and the $[\alpha]_{D}$ values are given in $10^{-1} \mathrm{deg} \mathrm{cm}^{2} \mathrm{~g}^{-1}$. UV spectra were obtained in absolute $\mathrm{EtOH}$ on a JASCO V-560 instrument. IR (film) spectra were measured in $\mathrm{CHCl}_{3}$ on a Bruker IFS 55 spectrophotometer. ${ }^{1} \mathrm{H}(400$ or $500 \mathrm{MHz})$ and ${ }^{13} \mathrm{C}(100$ or $125 \mathrm{MHz})$ NMR spectra were recorded on Bruker Avance 400 or 500 spectrometers; chemical shifts are given in ppm and coupling constants in hertz. Samples were dissolved $\left(\mathrm{CDCl}_{3}: \delta_{\mathrm{H}} 7.26, \delta_{\mathrm{C}} 77.0\right)$. EI-MS and EI-HRMS were recorded on a Micromass Autospec spectrometer. Silica gel 60 (particle size 15-40 $\mu \mathrm{m}$ ) for column chromatography and silica gel 60 F254 for analytical (TLC) and preparative thin-layer chromatography (PTLC) were purchased from Macherey-Nagel. Sephadex LH-20 was obtained from Pharmacia Biotech. Shimadzu high-performance liquid chromatography (HPLC) equipment consisted of a pump LKB 2248 solvent delivery module, SPD-6V detector set at $254 \mathrm{~nm}$, using a semipreparative silica gel column (Waters $\mu$-Porosil ${ }^{\circledR}, 15 \mathrm{~cm} \times 1.6 \mathrm{~mm}$, particle size $\left.10 \mu \mathrm{m}\right)$. The mobile phase consisted of a mixture of $n$-hexane-EtOAc (8:2) in isocratic mode with a flow rate of $9 \mathrm{~mL} / \mathrm{min}$. The degree of purity of the compounds was over 95\%, as indicated by a single peak in HPLC and NMR. All solvents used were of analytical grade (Panreac), and the reagents, used without purification, were purchased from Sigma-Aldrich. Pristimerin, used as starting material, was isolated from the root bark of $M$. blepharodes and M. canariensis, as previously described [20,21].

\subsection{Phenolic Nor-Triterpenes}

The natural phenolic nor-triterpenes 1 (6-oxopristimerol) [20,26], 3 (7,8-dihydro-6-oxoiguesterol, canarol) [27], 16 (6-oxotingenol) [20], 17 (3-O-methyl-6-oxotingenol) [20], and 20 (6-oxoiguesterol) [20] were isolated from the root bark of Maytenus canariensis, and compounds 2 (7-hydroxy-6-oxopristimerol) [21,28], 4 (blepharodol) [21], 5 (7 $\alpha$-hydroxyblepharodol) [27], 10 (blepharotriol) [21], 12 (zeylasteral) [27,29], 13 (demethylzeylasteral) [21,29], 14 (zeylaterone) [27,29], 15 (demethylzeylasterone) [21,29], 22 (7- 
oxoblepharodol) [21], and 25 (6-deoxoblepharodol) [21] from Maytenus blepharodes. Derivatives 11 (2,3O-dimethoxyblepharodol) [21], 18 (2,3-O-dimethyl-6-oxotingenol) [20], 19 (2,3-O-diacetoxy-6-oxoting enol) [20], 21 (2,3-O-dimethyl-6-oxoiguesterol) [20], 23 (2-O-methoxy-7-oxoblepharodol) [21], 24 (pristimerol) [21,30], and 26 (8-epi-6-deoxoblepharodol) [21] were obtained following the methodology previously described $[20,21]$. The structures of these compounds are depicted in Figure 2. Moreover, the semisynthesis of derivate 6 , not previously described, was achieved by acetylation of pristimerin, a main quinone-methide triterpene isolated from the root bark of Maytenus species [27]. In addition, derivatives 7-9 were prepared by catalytic reduction and further acetylation of pristimerin. Derivative 7 is a known synthetic compound [31] whose ${ }^{1} \mathrm{H}$ and ${ }^{13} \mathrm{C}$ NMR data have not been previously assigned, whereas derivatives 8 and $\mathbf{9}$ are reported herein for the first time (Scheme 1, Figures S1-S4.).

\subsubsection{Preparation of Compound 6}

To a stirred solution of pristimerin $(31.0 \mathrm{mg})$ in pyridine $(0.15 \mathrm{~mL})$, anhydride acetic $(0.1 \mathrm{~mL})$ and a catalytic amount of 4-dimethylamino-pyridine were added. The resulting orange-red solution was stirred for $14 \mathrm{~h}$ at room temperature, until TLC showed complete conversion. This yellow solution was concentrated under reduced pressure, and the residue was purified by preparative TLC using $n$-hexane-EtOAc (1:1) as eluent to afford compound 6 (14.0 $\mathrm{mg}, 37.0 \%)$.

$6 \alpha$-Hydroxy-2,3-diacetylpristimerol (6). Pale yellow amorphous solid; $[\alpha]_{\mathrm{D}}^{20}-39.7(c 0.15, \mathrm{MeOH})$; UV (EtOH) $\lambda_{\max }(\log \varepsilon) 340$ (7.3), 204 (7.4) nm; IR $v_{\max }$ (film) 3517, 2948, 2872, 1770, 1730, 1459, 1373, $1215,1106,758 \mathrm{~cm}^{-1} ;{ }^{1} \mathrm{H}$ NMR $\left(500 \mathrm{MHz}, \mathrm{CDCl}_{3}\right) \delta 0.59$ (3H, s, Me-27), 1.09 (3H, s, Me-28), $1.16(3 \mathrm{H}, \mathrm{s}$, Me-30), 1.24 (3H, s, Me-26), 1.35 (3H, s, Me-25), 2.29 (3H, s, OAc-3), 2.32 (3H, s, Me-23), 2.33 (3H, s, OAc-2), $3.54(3 \mathrm{H}, \mathrm{s}, \mathrm{OMe}-29), 5.06(1 \mathrm{H}, \mathrm{dd}, J=3.0,10.8 \mathrm{~Hz}, \mathrm{H}-6), 5.76(1 \mathrm{H}, \mathrm{d}, J=3.0 \mathrm{~Hz}, \mathrm{H}-7), 7.03(1 \mathrm{H}$, s, H-1). ${ }^{13} \mathrm{C}$ NMR (125 MHz, CDCl 3 ) $\delta 12.3$ (q, C-23), 18.6 (q, C-27), 20.7 (q, C-26), 21.0 (q, OAc-2), 21.6 (q, OAc-3), 29.1 (t, C-15), 30.2 (t, C-21), 30.4 (t, C-12), 30.9 (t, C-19), 31.2 (s, C-17), 31.9 (q, C-28), 33.1 (q, C-30), $34.5(\mathrm{t}, \mathrm{C}-22), 35.1(\mathrm{t}, \mathrm{C}-11), 36.9$ (t, C-16), 37.4 (q, C-25), 38.3 (s, C-9), 38.6 (s, C-13), 40.8 (s, C-20), 44.6 (d, C-18), 44.8 (s, C-14), 51.9 (q, OMe-29), 66.4 (d, C-6), 116.9 (d, C-1), 117.5 (s, C-7), 128.7 (s, C-4), 130.8 (s, C-5), 139.1 (s, C-3), 142.9 (s, C-2), 151.8 (s, C-10), 159.4 (s, C-8), 168.4 (s, OAc-2), 168.7 (s, OAc-3), 179.2 (s, C-29); EI-MS m/z (\%) 566 [M+] (39), 551 (14), 534 (52), 506 (32), 492 (100), 450 (42), 201 (95); EI-HRMS m/z 556.3032 (calcd. for $\mathrm{C}_{34} \mathrm{H}_{46} \mathrm{O}_{7}, 556.3048$ ).

\subsubsection{Preparation of Compounds 7-9}

A mixture of pristimerin $(622.0 \mathrm{mg})$ and $\mathrm{Pd} / \mathrm{C} 5 \%(100 \mathrm{mg})$ in acetic acid $(15 \mathrm{~mL})$ was stirred under 1 atmosphere of hydrogen for $3 \mathrm{~h}$. The reaction mixture was filtered through a pad of celite, the solution quenched by addition of saturated aqueous sodium bicarbonate solution, and the aqueous residue extracted with dichloromethane $(3 \times 30 \mathrm{~mL})$. Then, to the crude, pyridine $(1.5 \mathrm{~mL})$ dissolved in acetic anhydride $(1.5 \mathrm{~mL})$ was added, and the reaction mixture was stirred for $12 \mathrm{~h}$ at room temperature. Upon completion of the reaction, the solution was concentrated on a cold finger with liquid nitrogen. The residue was purified by HPLC using $n$-hexane-ethyl acetate (8:2) as eluent to give compound 7 $\left(21.9 \mathrm{mg}, 2.9 \%, \mathrm{t}_{\mathrm{R}}=11.4 \mathrm{~min}\right)$, reported elsewhere [31], and derivatives $8\left(76.4 \mathrm{mg}, 10.3 \%, \mathrm{t}_{\mathrm{R}}=12.3 \mathrm{~min}\right)$ and $9\left(32.1 \mathrm{mg}, 4.3 \%, \mathrm{t}_{\mathrm{R}}=12.6 \mathrm{~min}\right)$, not previously reported.

2,3-Diacetylpristimerol (7). Pale yellow amorphous solid; $[\alpha]_{\mathrm{D}}^{20}-15.5$ (c 0.15, MeOH); UV (EtOH) $\lambda_{\max }$ ( $\log \varepsilon) 278$ (7.3), 203 (7.4), 201 (7.3) nm; IR $v_{\max }$ (film) 2927, 2870, 1775, 1729, 1649, 1371, 1214, 1188, 756 $\mathrm{cm}^{-1} ;{ }^{1} \mathrm{H}$ NMR $\left(500 \mathrm{MHz}, \mathrm{CDCl}_{3}\right) \delta 0.58(3 \mathrm{H}, \mathrm{s}, \mathrm{Me}-27), 1.08$ (3H, s, Me-28), 1.17 (3H, s, Me-30), 1.22 (3H, s, Me-26), 1.35 (3H, s, Me-25), 2.06 (3H, s, Me-23), 2.28 (3H, s, OAc-2), 2.31 (3H, s, OAc-3), 3.06 (1H, $\mathrm{d} \mathrm{br}, J=15.7 \mathrm{~Hz}, \mathrm{H}-6 \beta), 3.32(1 \mathrm{H}, \mathrm{dd}, J=5.1,15.7 \mathrm{~Hz}, \mathrm{H}-6 \alpha), 3.55(3 \mathrm{H}, \mathrm{s}, \mathrm{OMe}-29), 5.73(1 \mathrm{H}, \mathrm{d}, J=5.1$ $\mathrm{Hz}, \mathrm{H}-7), 7.00(1 \mathrm{H}, \mathrm{s}, \mathrm{H}-1) .{ }^{13} \mathrm{C}$ NMR $\left(100 \mathrm{MHz}, \mathrm{CDCl}_{3}\right) \delta 12.5$ (q, C-23), 18.2 (q, C-27), 20.4 (q, OAc-2), 20.7 (q, OAc-3), 22.7 (q, C-26), 28.1 (t, C-6), 28.9 (t, C-15), 30.2 (t, C-12), $30.2(\mathrm{t}, \mathrm{C}-19), 30.5(\mathrm{t}, \mathrm{C}-22), 31.6$ (q, C-28), 32.8 (q, C-30), 34.3 (q, C-25), $34.4(\mathrm{t}, \mathrm{C}-11), 34.8(\mathrm{~s}, \mathrm{C}-17), 34.8(\mathrm{t}, \mathrm{C}-21), 36.8(\mathrm{t}, \mathrm{C}-16), 37.2(\mathrm{~s}$, C-13), 37.5 (s, C-9), 40.4 (s, C-20), 43.7 (s, C-14), 44.4 (d, C-18), 51.5 (q, OMe-29), 116.7 (d, C-1), 116.9 (d, 
C-7), 127.8 (s, C-4), 131.5 (s, C-5), 138.0 (s, C-3), 140.6 (s, C-2), 147.5 (s, C-10), 149.0 (s, C-8), 168.4 (s, OAc-2), 168.7 (s, OAc-3), 178.9 (s, C-29); EI-MS m/z (\%): 550 [M+1 ] (1), 535 (8), 475 (16), 322 (7), 229 (17), 149 (9), 57 (100); EI-HRMS m/z 550.3167 (calcd. for $\mathrm{C}_{34} \mathrm{H}_{46} \mathrm{O}_{6}, 550.3192$ ).

2,3-Diacetyl-6-deoxoblepharodol (8). Pale yellow amorphous solid; $[\alpha]_{\mathrm{D}}^{20}-29.5$ (c 0.20, MeOH); UV (EtOH) $\lambda \max (\log \varepsilon) 278$ (7.3), 203 (7.3), 201 (7.2) nm; IR vmax (film) 2937, 1773, 1730, 1462, 1371, 1213, 1040, $756 \mathrm{~cm}^{-1} ;{ }^{1} \mathrm{H}$ NMR (500 MHz, CDCl $) \delta 0.78(3 \mathrm{H}, \mathrm{s}, \mathrm{Me}-27), 0.88(3 \mathrm{H}, \mathrm{s}, \mathrm{Me}-26), 1.10(3 \mathrm{H}, \mathrm{s}$, Me-28), 1.60 (6H, s, Me-25, Me-30), 1.98 (3H, s, Me-23), 2.26 (3H, s, OAc-3), 2.30 (3H, s, OAc-2), 2.59 (1H, $\mathrm{dd}, J=11.8,15.7 \mathrm{~Hz}, \mathrm{H}-6 \alpha), 2.60(1 \mathrm{H}, \mathrm{dd}, J=6.1,15.7 \mathrm{~Hz}, \mathrm{H}-6 \alpha), 3.59(3 \mathrm{H}, \mathrm{s}, \mathrm{OMe}), 6.89(1 \mathrm{H}, \mathrm{s}, \mathrm{H}-1)$. ${ }^{13} \mathrm{C}$ NMR (100 MHz, CDCl $\left.{ }_{3}\right) \delta 12.5$ (q, C-23), 15.9 (q, C-26), 17.3 (q, C-27), 18.2 (t, C-7), 20.4 (q, OAc-3), 20.6 (q, OAc-2), 27.3 (q, C-25), $28.6(\mathrm{t}, \mathrm{C}-6), 28.9$ (t, C-21), 30.0 (t, C-12), 30.1 (s, C-17), $30.2(\mathrm{t}, \mathrm{C}-19), 30.5$ (t, C-15), 31.8 (q, C-28), 31.9 (q, C-30), 33.8 (t, C-11), 36.2 (t, C-22), $36.5(\mathrm{t}, \mathrm{C}-16), 37.2(\mathrm{~s}, \mathrm{C}-9), 38.9$ (s, C-13), 39.4 (s, C-14), 40.5 (s, C-20), 43.5 (d, C-8), 44.5 (d, C-18), 51.5 (q, OMe-29), 116.2 (d, C-1), 129.4 (s, C-4), 132.7 (s, C-5), 138.0 (s, C-3), 139.9 (s, C-2), 149.7 (s, C-10), 168.4 (s, OAc-3), 168.8 (s, OAc-2), 179.1 (s, C-29); EI-MS m/z (\%) 552 [M+1 ] (10), 510 (49), 495 (5), 468 (100), 453 (15), 249 (26), 190 (9); EI-HRMS $\mathrm{m} / \mathrm{z} 552.3457$ (calcd. for $\mathrm{C}_{34} \mathrm{H}_{48} \mathrm{O}_{6}, 552.3451$ ).

2,3-Diacetyl-8-epi-6-deoxoblepharodol (9). Pale yellow amorphous solid; $[\alpha]_{\mathrm{D}}^{20}-29.5$ (c 0.20, MeOH); UV (EtOH) $\lambda_{\max }(\log \varepsilon) 277$ (9.4), 203 (9.4), 200 (9.4) nm; IR $v_{\max }$ (film) 2956, 1771, 1728, 1643, 1370, 1214, 1184, 1039, $757 \mathrm{~cm}^{-1} ;{ }^{1} \mathrm{H}$ NMR (500 MHz, $\left.\mathrm{CDCl}_{3}\right) \delta 0.81(3 \mathrm{H}, \mathrm{s}, \mathrm{Me}-27), 0.88$ (2H, m, H-22), 1.08 (3H, s, Me-28), 1.16 (3H, s, Me-30), 1.21 (3H, s, Me-26), $1.42(1 \mathrm{H}, \mathrm{m}, \mathrm{H}-8) 1.46$ (3H, s, Me-25), 1.49 (1H, m, H-18), 1.58 (1H, m, H-19ß), 1.86 (2H, m, H-16), 2.02 (3H, s, Me-23), 2.21 (2H, m, H-22), 2.26 (3H, s, OAc-3), 2.29 (3H, s, OAc-2), 2.35 (1H, d br, H-19 $\alpha), 2.72(2 \mathrm{H}, \mathrm{m}, J=16 \mathrm{~Hz}, \mathrm{H}-6), 3.56$ (3H, s, OMe), 6.98 $(1 \mathrm{H}, \mathrm{s}, \mathrm{H}-1) .{ }^{13} \mathrm{C}$ NMR $\left(100 \mathrm{MHz}, \mathrm{CDCl}_{3}\right) \delta 12.6$ (q, C-23), 18.9 (q, C-27), 20.4 (q, OAc-2), 20.7 (q, OAc-3), $26.5(\mathrm{t}, \mathrm{C}-12), 25.8$ (q, C-26), 28.6 (t, C-6), $30.0(\mathrm{t}, \mathrm{C}-12), 30.1(\mathrm{t}, \mathrm{C}-6), 30.2(\mathrm{t}, \mathrm{C}-15), 30.5(\mathrm{t}, \mathrm{C}-7), 30.6(\mathrm{t}$, C-19), 30.7 (s, C-17), 30.8 (t, C-21), 31.3 (q, C-28), 32.8 (q, C-30), 33.3 (t, C-11), 36.8 (q, C-25), 35.7 (t, C-22), 37.1 (t, C-16), 38.3 (s, C-14), 38.7 (s, C-9), 40.4 (s, C-13), 40.6 (s, C-20), 46.7 (d, C-18), 51.5 (q, OMe-29), 56.0 (d, C-8), 1193 (d, C-1), 128.0 (s, C-4), 135.4 (s, C-5), 137.5 (s, C-3), 140.2 (s, C-2), 148.5 (s, C-10), 168.4 (s, OAc-2), 168.8 (s, OAc-3), 180.7 (s, C-29); EI-MS m/z (\%) 552 [M+ $\mathrm{M}^{+}$(9), 510 (43), 495 (10), 468 (100), 453 (22), 435 (6), 287 (13), 249 (25), 190 (22); EI-HRMS m/z 552.3457 (calcd. for $\mathrm{C}_{34} \mathrm{H}_{48} \mathrm{O}_{6}, 552.3451$ ).

\subsection{Antimicrobial Activity}

Strains used for determining antimicrobial activity included Bacillus subtilis ATCC 6051, B. alvei ATCC 6344, B. cereus ATCC 21772, B. megaterium ATCC 25848, B. pumilus ATCC 7061, Staphylococcus aureus ATCC 6538, S. epidermidis ATCC 14990, S. saprophyticus ATCC 15305, Enterococcus faecalis ATCC 29212, Mycobacterium smegmatis ATCC 19420, Escherichia coli ATCC 9637, Proteus mirabilis CECT 170, (from Type Culture Spanish Collection), Pseudomonas aeruginosa AK 958 (from the University of British Columbia, Department of Microbiology collection), Salmonella sp. CECT 456, Klebsiella oxytoca LMM2 (clinical isolate, University of La Laguna), and Candida albicans CECT 1039. The bacteria cultures were developed in nutrient broth (NB) or brain heart infusion broth (for E. faecalis and M. smegmatis containing $0.06 \%$ Tween 80 ), and the yeast was cultured in Sabouraud liquid medium at $37^{\circ} \mathrm{C}$. All culture media were purchased from Oxoid. The minimum inhibitory concentrations (MICs) were determined for each compound in triplicate by broth microdilution method (range 0.08-40 $\mu \mathrm{g} / \mathrm{mL}$ ) in 96 well microtitre plates, according to the M07-A9 of the CLSI (Clinical and Laboratory Institute) [32]. Wells with the same proportions of dimethyl sulfoxide (DMSO) were used as controls and never exceeded $1 \%(v / v)$. The starting microorganism concentration was approximately $1-5 \times 10^{5} \mathrm{CFU} / \mathrm{mL}$, and growth was monitored by measuring the increase in optical density (OD) at $550 \mathrm{~nm}\left(\mathrm{OD}_{550}\right)$ with a microplate reader (Multiskan Plus II, Tritertek, Huntsville, AL, USA) and viable count in agar plates. The MIC was defined as the lowest concentration of compound that completely inhibits growth of the organisms compared with that of the control after incubation time. 


\section{Results and Discussion}

\subsection{Chemistry}

Compounds 1-5, 10, 12-17, 20, 22, and 25 (Figure 2) were isolated, purified, and characterized in our laboratory from two Maytenus species, M. blepharodes and M. canariensis, as previously described [20, 21,27]. Derivatives 11, 18, 19, 21, 23, 24, and 26, achieved by acetylation or methylation from natural compounds, are described by González et al. [20] and Rodríguez et al. [21]. Moreover, derivatives 6-9 were prepared from pristimerin (Scheme 1). The semisynthesis of $\mathbf{6}$ was achieved by acetylation of pristimerin, and derivatives 7-9 were obtained by catalytic reduction and further acetylation of pristimerin, as described in the experimental section. Their structures were greatly aided by comparison of their spectroscopic data with those previously reported for related compounds 24-26 [21]. Even so, a complete set of two-dimensional (2D) NMR spectra (COSY, ROESY, HSQC and HMBC) was acquired for the new derivatives to gain the complete assignment of the ${ }^{1} \mathrm{H}$ and ${ }^{13} \mathrm{C}$ NMR resonances (see Experimental Section, Figures S1-S4). Derivative 7 was identified as the previously described 2,3-diacetylpristimerol [31], however, its ${ }^{1} \mathrm{H}$ and ${ }^{13} \mathrm{C}$ NMR assignments have not been previously reported. Moreover, derivatives 6, 8, and 9 are described herein for the first time, and their structures were elucidated as described below.

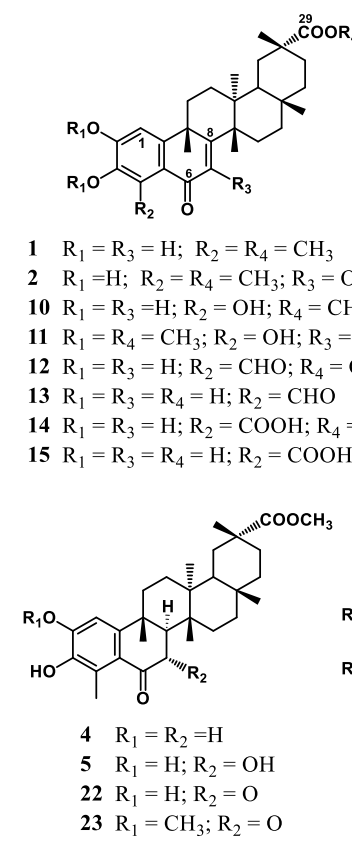

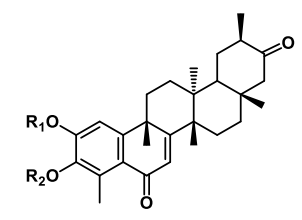

$16 \mathrm{R}_{1}=\mathrm{R}_{2}=\mathrm{H}$

$17 \mathrm{R}_{1}=\mathrm{H} ; \mathrm{R}_{2}=\mathrm{CH}_{3}$

$18 \mathrm{R}_{1}=\mathrm{R}_{2}=\mathrm{CH}_{3}$

$19 \mathrm{R}_{1}=\mathrm{R}_{2}=\mathrm{Ac}$

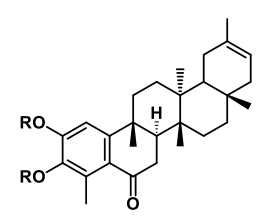

$3 \mathrm{R}=\mathrm{H}$

$20 \mathrm{R}=\mathrm{H}, \Delta^{7}$

$21 \mathrm{R}=\mathrm{CH}_{3}, \Delta^{7}$

$11 \mathrm{R}_{1}=\mathrm{R}_{4}=\mathrm{CH}_{3} ; \mathrm{R}_{2}=\mathrm{OH} ; \mathrm{R}_{3}=\mathrm{H}$

$12 \mathrm{R}_{1}=\mathrm{R}_{3}=\mathrm{H} ; \mathrm{R}_{2}=\mathrm{CHO} ; \mathrm{R}_{4}=\mathrm{CH}_{3}$

$13 \mathrm{R}_{1}=\mathrm{R}_{3}=\mathrm{R}_{4}=\mathrm{H} ; \mathrm{R}_{2}=\mathrm{CHO}$

$14 \mathrm{R}_{1}=\mathrm{R}_{3}=\mathrm{H} ; \mathrm{R}_{2}=\mathrm{COOH} ; \mathrm{R}_{4}=\mathrm{CH}_{3}$

$15 \mathrm{R}_{1}=\mathrm{R}_{3}=\mathrm{R}_{4}-\mathrm{H} ; \mathrm{R}_{2}=\mathrm{COOH}$

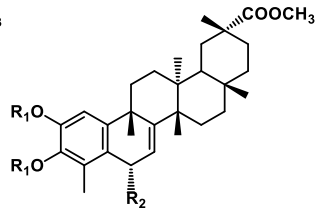

$6 \mathrm{R}_{1}=\mathrm{Ac} ; \mathrm{R}_{2}=\mathrm{OH}$

$7 \mathrm{R}_{1}=\mathrm{Ac} ; \mathrm{R}_{2}=\mathrm{H}$

$24 \mathrm{R}_{1}=\mathrm{R}_{2}=\mathrm{H}$

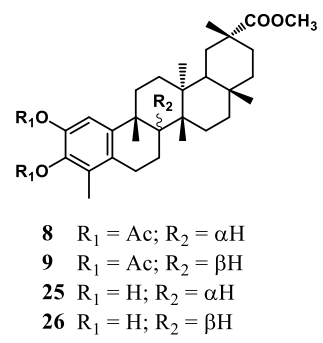

Figure 2. Natural and derivatives phenolic nor-triterpenes included in the SAR studies. SAR: structureactivity relationship.

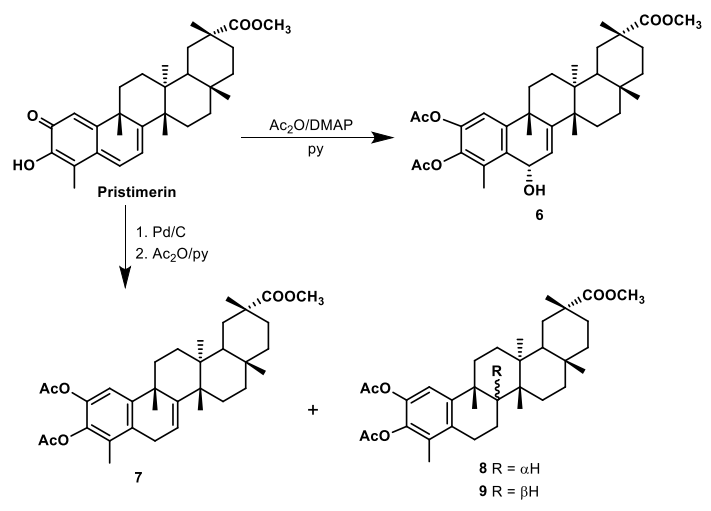

Scheme 1. Synthesis of analogues 6-9 from pristimerin. 
Derivative 6 was obtained as a pale yellow amorphous solid with $[\alpha]_{\mathrm{D}}^{20}-39.7$ (c $\left.0.15, \mathrm{MeOH}\right)$. The molecular formula, $\mathrm{C}_{34} \mathrm{H}_{46} \mathrm{O}_{7}$, was established by EI-HRMS $\left(\mathrm{m} / z 556.3048\right.$ [ $\mathrm{M}^{+}$], calcd. 556.3032). The IR absorptions revealed the presence of hydroxyl $\left(3517 \mathrm{~cm}^{-1}\right)$ and ester carbonyl $(1770$ and $\left.1730 \mathrm{~cm}^{-1}\right)$ groups and an aromatic ring $\left(1459\right.$ and $\left.758 \mathrm{~cm}^{-1}\right)$. Two acetoxy and a carboxylic methyl ester group in 6 were evident from the ${ }^{1} \mathrm{H}$ NMR signals at $\delta 2.29(3 \mathrm{H}, \mathrm{s}), 2.33(3 \mathrm{H}, \mathrm{s})$, and $3.54(3 \mathrm{H}, \mathrm{s})$, in combination with those in the ${ }^{13} \mathrm{C}$ NMR $(\delta 20.6,21.0,51.9,168.4$, and 168.7). Besides the carbons of acetoxy and methoxy groups, the ${ }^{13} \mathrm{C}$ NMR and DEPT data revealed 29 carbon resonances, including one carboxylic carbon, one aromatic ring, one trisubstituted double bond, one oxymethine carbon, five $\mathrm{sp}^{3}$ quaternary carbons, one methine, seven methylenes, and six methyls. Analysis of 2D NMR data, including HSQC, ${ }^{1} \mathrm{H}_{-}{ }^{1} \mathrm{H}$ COSY, ROESY, and HMBC experiments, and comparison with data reported for pristimerol (24) [30] indicated that 6 is a phenolic triterpene with a pristimerin framework. In particular, HMBC correlations of Me-23 with C-3, C-4, and C-5; H-1 with C-2, C-3, C-5, C-9, and C-10; H-6 with C-4, C-5, C-8, and C-10, and correlations of Me-25 with C-8, C-9, and C-10 established the structure of $A$ and $B$ rings. The regiosubstitution of the acetate groups and the relative configuration of H-6 were deduced by a ROESY experiment, showing ROEs (Rotating-frame Overhauser Effects) between H-6/OMe-25, H-1/OAc-2, and Me-23/OAc-3 (Figure 3). Thus, the structure of 6 was established as $6 \alpha$-hydroxy-2,3-diacetoxy-pristimerol.

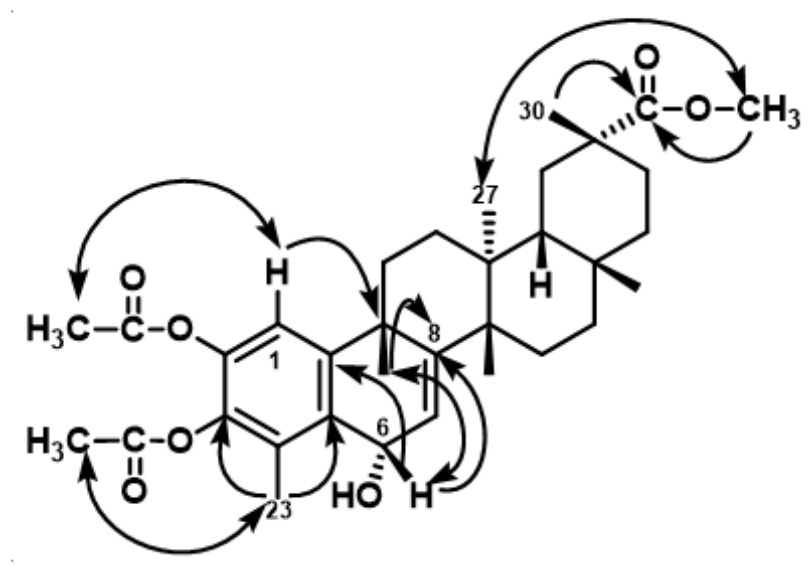

Figure 3. Selected HMBC (single arrow) and ROE (doubled arrow) correlations for compound 6.

Derivative 7 was assigned the molecular formula $\mathrm{C}_{34} \mathrm{H}_{46} \mathrm{O}_{6}$, determined by EI-HRMS. The mass spectrum exhibited peaks characteristic to acetate groups $\left(\mathrm{M}^{+}-15-60, \mathrm{~m} / \mathrm{z} 475, \mathrm{CH}_{3}, \mathrm{CH}_{3} \mathrm{COOH}\right)$. This was confirmed by the ${ }^{1} \mathrm{H}$ and ${ }^{13} \mathrm{C}$ NMR spectra, which included signals for two acetyl groups $\left(\delta_{\mathrm{H}}\right.$ $\left.2.28(\mathrm{~s}), 2.31(\mathrm{~s}), \delta_{\mathrm{C}} 20.4(\mathrm{q}), 20.7(\mathrm{q}), 168.4(\mathrm{q}), 168.7(\mathrm{~s})\right)$. Its ${ }^{1} \mathrm{H}$ NMR spectrum showed signals for six methyl groups $\left(\delta_{\mathrm{H}} 0.58,1.08,1.17,1.22,1.35\right.$, and 2.06$)$, a methoxy group at $\delta_{\mathrm{H}} 3.55$, a vinylic proton at $\delta_{\mathrm{H}} 5.73(\mathrm{~d}, J=5.1 \mathrm{~Hz})$, and an aromatic proton at $\delta_{\mathrm{H}} 7.00(\mathrm{~s})$. The ${ }^{13} \mathrm{C}$ NMR spectrum displayed 34 signals, which were assigned to one methoxy, eight methyls, eight methylenes, three methines, and fourteen quaternary carbons, including six $s p^{2}$ and three carboxylic carbons. Extensive study of the ${ }^{2,3} J_{\mathrm{C}-\mathrm{H}}$ correlations (HMBC) allowed us to establish the structure of A and B rings and build the nor-triterpene skeleton for 7 . The regiosubstitution of the acetate groups was deduced by a ROESY experiment, showing ROE effects between $\mathrm{H}-1 / \mathrm{OAc}-2$ and Me-23/OAc-3. This data established the structure of 7 as 2,3-diacetoxy-pristimerol.

Compounds 8 and 9 , both with the molecular formula $\mathrm{C}_{34} \mathrm{H}_{48} \mathrm{O}_{6}$ (EI-HRMS), differ from that of 7 by the presence of two additional hydrogen atoms. The most remarkable difference in their NMR spectra, when compared to that of compound 7 , was the absence of the double bond C-7-C-8. Thus, in the ${ }^{13} \mathrm{C}$ NMR spectra of 8 and 9 , the signals assigned to $\mathrm{C}-7$ and $\mathrm{C}-8$ resonated in the region of aliphatic carbons $\left(\delta_{C} 18.2\right.$ and 43.5 in 8 , and $\delta_{C} 30.5$ and 56.0 in 9). Moreover, differences between 8 and 9 were also observed for the chemical shifts of Me- $25\left(\delta_{\mathrm{H}} 1.60, \delta_{\mathrm{C}} 27.3\right.$ in 8 , and $\delta_{\mathrm{H}} 1.46, \delta_{\mathrm{C}} 36.8$ in 9$)$ and 
Me-26 $\left(\delta_{\mathrm{H}} 0.88, \delta_{\mathrm{C}} 15.9\right.$ in 8 , and $\delta_{\mathrm{H}} 1.21, \delta_{\mathrm{C}} 25.8$ in 9$)$. Analysis of 2D COSY, HSQC, and HMBC spectra allowed us to define their core structures. The ROE effects of H-8/Me-25 and Me-26 observed in a ROESY experiment for compound 8, and those of $\mathrm{H}-8 / \mathrm{Me}-27$ observed for compound $\mathbf{9}$, further supported the stereochemical assignment for epimers 8 and $\mathbf{9}$. Their structures were also confirmed by chemical correlations; hydrolysis of $\mathbf{8}$ and $\mathbf{9}$ yielded compounds whose spectroscopic data were identical to those previously reported for 6-deoxoblepharodol (25) and 8-epi-6-deoxoblepharodol (26) [21], respectively. Consequently, the structure of compounds 8 and 9 were deduced to be 2,3-diacetyl-6-deoxoblepharodol and 2,3-diacetyl-8-epi-6-deoxoblepharodol, respectively.

\subsection{Antimicrobial Evaluation}

Compounds 1-9 were tested on Gram-positive and Gram-negative bacteria, and the yeast Candida albicans by the broth microdilution method. Moreover, compounds 24-26, closely related to 6-9, were also assayed against B. alvei, B. megaterium, and B. pumilus for SAR studies. The results (see Table 1) showed that spore-forming bacteria, such as the genus Bacillus are more sensitive to these compounds, among which compounds 6 and 24 exhibiting higher activity (MIC values of 1 and $2.5 \mu \mathrm{g} / \mathrm{mL}$ against B. subtilis and B. cereus, respectively) than cephotaxime, used as a positive control. Furthermore, the effectiveness against the Gram-positive cocci was restricted to compound 6 (S. epidermidis and E. faecalis, MIC 5-2.5 and 20-10 $\mu \mathrm{g} / \mathrm{mL}$, respectively). On the other hand, compounds 1-9 were inactive against the Gram-negative bacteria and the yeast C. albicans (MIC $>40 \mu \mathrm{g} / \mathrm{mL}$ ), which is in line with previous studies on this type of compound [20-23,25].

Table 1. Minimal inhibitory concentration (MIC, $\mu \mathrm{g} / \mathrm{mL})^{1}$ against Gram-positive bacteria of phenolic nor-triterpenes ${ }^{2}$ and lipophilicity $(\operatorname{clog} P)$.

\begin{tabular}{|c|c|c|c|c|c|c|c|c|c|c|c|}
\hline Compound & S. $a$. & S.e. & S. s. & E.f. & B. s. & B. $a$. & B. $c$. & B. $m$. & B. $p$. & $\operatorname{clog} P$ & Reference \\
\hline 2 & $>40$ & $>40$ & $>40$ & $>40$ & $40-20$ & $>40$ & $40-20$ & 40 & $>40$ & 5.43 & \\
\hline 3 & $>40$ & $>40$ & $>40$ & $>40$ & $40-20$ & $>40$ & 40 & $>40$ & $>40$ & 6. 41 & \\
\hline 5 & $>40$ & $>40$ & $>40$ & $>40$ & $40-20$ & $>40$ & $>40$ & $>40$ & $>40$ & 5.26 & \\
\hline 6 & $>40$ & $5-2.5$ & $>40$ & 20-10 & 1 & $20-10$ & 2.5 & $10-5$ & $10-5$ & 5.95 & \\
\hline 10 & $>40$ & $>40$ & $>40$ & $>40$ & $8-4$ & - & $>40$ & - & - & 5.42 & [21] \\
\hline 12 & 40 & 20 & $>40$ & $>40$ & 10 & 7 & 12 & 20 & 25 & 5.67 & [22] \\
\hline 13 & 25 & 20 & 40 & $>40$ & 13 & $>40$ & 20 & $>40$ & 10 & 5.04 & [22] \\
\hline 14 & 6 & $>40$ & $>40$ & $>40$ & 3 & 4 & 5 & 4 & 6 & 5.21 & [23] \\
\hline 15 & $>40$ & $>40$ & $>40$ & $>40$ & 13 & $>40$ & 30 & $>40$ & $>40$ & 4.67 & [23] \\
\hline 16 & $>40$ & $>40$ & $>40$ & $>40$ & 14-12 & - & $>40$ & $>40$ & $>40$ & 5.58 & [20] \\
\hline 17 & $>40$ & $>40$ & $>40$ & $>40$ & 39-35 & - & $>40$ & $>40$ & $>40$ & 6.20 & [20] \\
\hline 20 & $>40$ & $>40$ & $>40$ & $>40$ & 25 & - & 40 & $>40$ & $>40$ & 6.86 & [20] \\
\hline 22 & 30 & $>40$ & $>40$ & - & $8-4$ & - & 10 & - & - & 5.79 & [21] \\
\hline 24 & $>40$ & 0.625 & $10-5$ & $>40$ & $1-0.5$ & $5-2.5$ & 2.5 & 20-10 & $5-2.5$ & 7.09 & [21] \\
\hline 25 & $>40$ & 20-10 & $>40$ & $>40$ & $10-5$ & $40-20$ & 20-10 & $>40$ & $20-10$ & 6.41 & [21] \\
\hline 26 & $>40$ & 2 & 20-10 & $>40$ & $5-2.5$ & $10-5$ & $10-5$ & $40-20$ & $>40$ & 6.41 & [21] \\
\hline Control $^{3}$ & 2.5 & 2.5 & 0.6 & $>20$ & 8 & - & 10 & - & $>20$ & 0.14 & \\
\hline
\end{tabular}

S. a.: Staphylococcus aureus, S. e.: S. epidermidis, S. s.: S. saprophyticus, E. f.: Enterococcus faecalis, B. s.: Bacillus subtilis, B. a.: B. alvei, B. c.: B. cereus, B. m.: B. megaterium, B. p.: B. pumilus.- not assayed. ${ }^{1}$ The experiments were carried out in triplicate, and values represent average of MIC values. ${ }^{2}$ All compounds were inactive against Gram-negative bacteria (MIC > $40 \mu \mathrm{g} / \mathrm{mL}$ ). Compounds $(\operatorname{cog} P) \mathbf{1}(6.15), 4$ (6.07), 7-9 (7.18, 6.90 and 6.90), 11 (6.38), 18 (6.47), 19 (5.44), 21 (7.17), and 23 (5.72) were inactive against all microorganisms assayed. ${ }^{3}$ Cephotaxime was used as a positive control.

\subsection{Structure-Activity Relationship Analysis}

The influence of substitution patterns of the phenolic nor-triterpenes on their antimicrobial activity was analyzed, taking into account three regions of the triterpene skeleton, the phenolic moiety, the extended B-ring conjugation, and the triterpene scaffold (pristimerin, tingenone, or iguesterin). This analysis revealed the following trends in the structure-activity relationship (SAR) (Figure 4). Regarding the results obtained against Bacillus spp., the SAR studies suggest that: (a) A substituent at C-4 seems essential for the activity. Thus, comparison of the activities (MICs against B. subtilis) of 14, 10,12 , and 1 , whose only structural difference is the substituent at $C 4$, showed that the most effective 
group at this position was a carboxylic acid (14), followed by hydroxyl (10) and aldehyde (12) groups, while a methyl group, as in $\mathbf{1}$, led to a loss of activity. B. cereus, B. alvei, B. megaterium, and B. pumilus showed similar behavior to $B$. subtilis (14 vs. 12); (b) Acetylation and methylation reduce activity, as revealed by comparison of potency of the natural compounds with their corresponding analogues ( $7 \mathrm{vs}$. 24,8 vs. 25,9 vs. 26,10 vs. 11,16 vs. 17, 18, 19, and 20 vs. 21), except for compound 6 with an hydroxyl group at $\mathrm{C} 6$ (6 vs. 7). This indicates that the hydroxyl group, which could interact with the receptor as hydrogen-bond-donor (HBD), is the best functional group, suggesting that the hydrophilicity is relevant for the activity; (c) Compounds with an unconjugated double bond at $\mathrm{C}-7$ showed considerable activity (e.g., $\mathbf{6}$ and 24), and reduction at C-7/C-8 results in a partial loss of antimicrobial activity (24 vs. 25 and 26); (d) The $\beta$-stereochemistry at C-8 increases two-fold the activity with respect to the $\mathrm{H}-8 \alpha$, as shown by comparing the MIC values of 26 and 25; (e) A substituent at C-7, in addition to the carbonyl at C-6, is also relevant for the activity, being a ketone preferred to a hydroxyl group ( $22>5$ vs. 4 ).
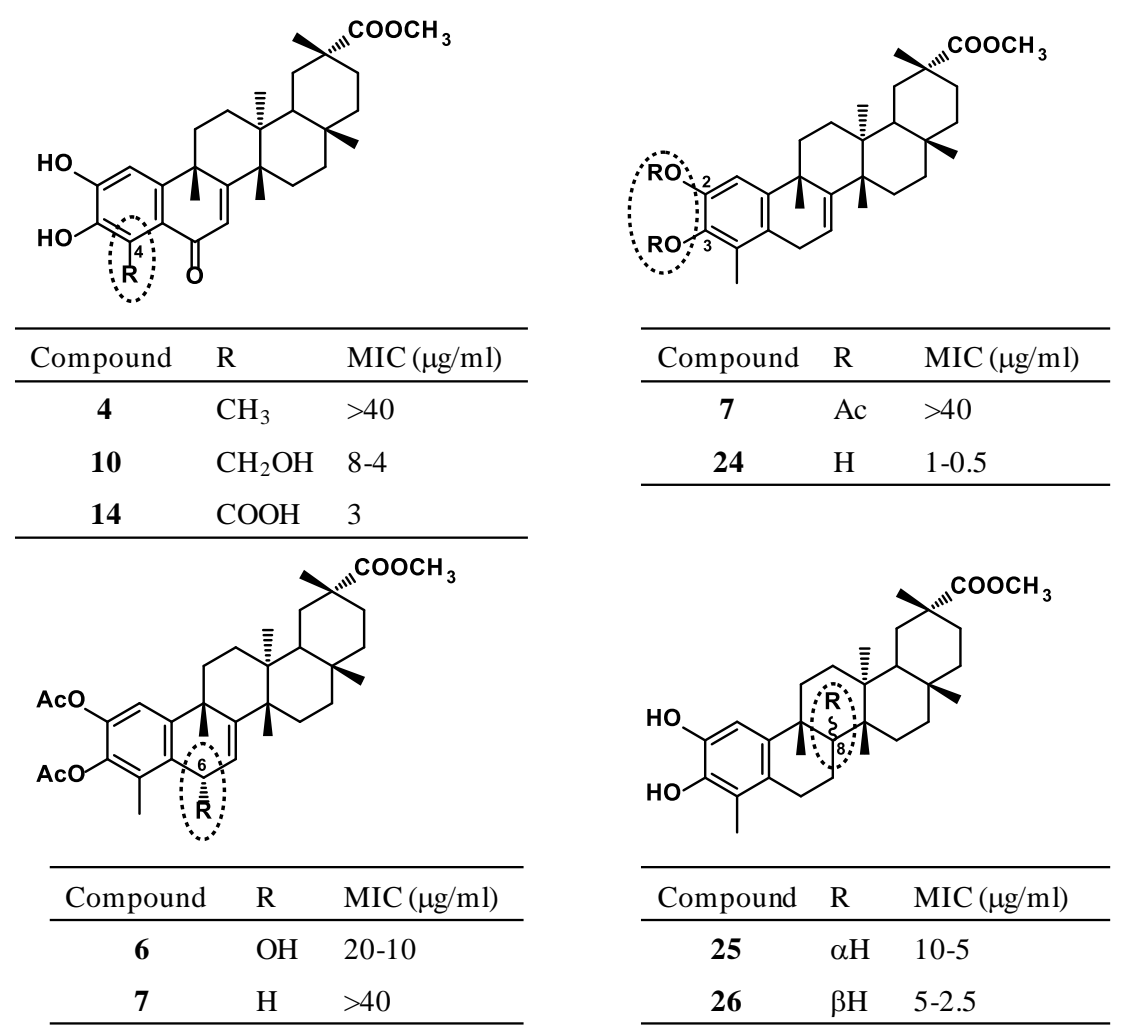

Figure 4. Most relevant structural features for phenolic nor-triterpenes against the most sensitive microorganism, Bacillus subtilis.

Furthermore, the results obtained against Staphylococcus spp. suggest that: (a) the presence of a carboxylic acid moiety at C-4 could strongly affect the antimicrobial activity against $S$. aureus since its substitution by an aldehyde or a methyl group reduced or fully eliminated the activity (14 vs. 12 or 1); (b) moreover, replacement of the carboxyl group at C-29 by its methyl ester led to a partial loss of activity (13 vs. 12); (c) compounds containing two carboxylic acid groups lacked activity, whereas those with one carboxylic acid showed high activity (14 vs. 15); (d) the reduction of the double bond at C-7/C-8 led to less activity (24 vs. 25 and 26 against S. epidermidis); (e) the $\beta$-stereochemistry at the C-8 position favored the activity with respect to the H-8 $\alpha$ (26 vs. 25); (f) a hydroxyl group at C-6 affected the activity against $S$. epidermidis ( 6 vs. 7 ). Taking into account these structural features, we propose a hypothetical compound, 4-carboxy- $6 \alpha$-hydroxy-pristimerol, that would have a zeylasterone A-ring (as in 14), an unconjugated B-ring (as in $\mathbf{6}$ and 24), and a pristimerin E-ring as being the most active against Bacillus and Staphylococcus spp. (Figure 5). 


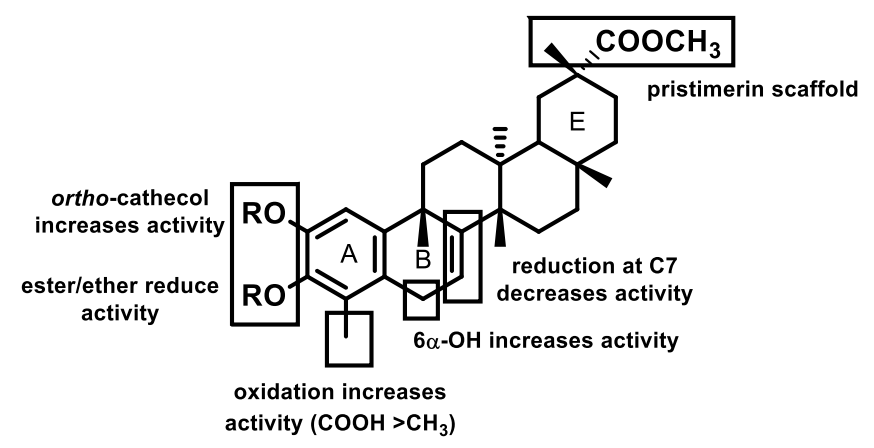

Figure 5. Structural requirements of phenolic nor-triterpenes based on SAR studies.

Some phenolic compounds primarily target the cytoplasmic membrane due to their hydrophobic nature, and preferentially partition into the lipid bilayer [33], as was observed in our previous works [22-25]. Therefore, for the purpose of correlating the antimicrobial activity with lipophilicity, clog $P$ values [34] of this series of compounds were calculated, including that of the hypothetical compound, 4-carboxy- $6 \alpha$-hydroxy-pristimerol (clog $P 4.88)$, and are shown in Table 1. Slight increases in lipophilicity of $\mathbf{2 4}$ (clog $P$ 7.09) and 25 and 26 ( $\log P$ 6.41) by acetylation (7, 8 and $\mathbf{9}$, respectively) ( $\log P 7.18$ and 6.90) led to a suppression of the antibacterial activity. Moreover, other factors must be taken into account for the expression of the activity, such as the presence of an hydrogen-bond donor (HBD) group, strategically positioned at C-4 (e.g., 14), C-6 (e.g., 6), or at C-2 and C-3 (e.g., 12 and 14) with $\operatorname{cog} P$ of 5.04,5.95, and 5.67, respectively, which seems relevant for the activity. These observations indicated that both lipophilicity and HBD factors are involved in the antimicrobial activity of this type of compound.

\section{Conclusions}

In summary, the antimicrobial activity of five phenolic nor-triterpenes isolated from two Maytenus species and those of four derivatives revealed that compound 6 showed significant activity against Gram-positive bacteria, higher than cephotaxime, used as positive control. In order to understand and further optimize the structural requirements for effective inhibition of bacterial growth in vitro, an extensive SAR analysis of a series of nor-triterpene phenols was performed. This study suggests that the phenolic moiety and carboxyl group at $\mathrm{C}-4$ on the A-ring, a nonconjugated double bond system on the B-ring, and the ring E, characteristic of pristimerin series, all contribute to the antimicrobial effectiveness. Based on these findings, we propose a hypothetical lead compound, 4-carboxy- $6 \alpha$-hydroxy-pristimerol. This comprehensive SAR study supports the future rational design of antimicrobial agents based on the phenolic nor-triterpene scaffold.

Supplementary Materials: The following are available online at http://www.mdpi.com/2076-3417/9/15/2957/s1, Figures S1-S4: ${ }^{1} \mathrm{H}$ and ${ }^{13} \mathrm{C}$ NMR spectra of derivatives 6-9.

Author Contributions: Conceptualization, L.M. and I.L.B.; methodology, L.M. and I.A.J.; investigation, M.R.L. and C.P.R.; data curation, L.M. and I.A.J.; writing-original draft preparation, I.L.B.; writing-review and editing, I.L.B. and L.M.; supervision, L.M. and I.L.B.; and funding acquisition, I.L.B.

Funding: This study was supported by SAF2015-65113-C2-1-R and RTI2018-094356-B-C21 Spanish MINECO co-funded by the European Regional Development Fund (FEDER) projects.

Acknowledgments: C.P.R. thanks the Cabildo de Tenerife (Agustín de Betancourt Program).

Conflicts of Interest: The authors declare no conflict of interest

\section{References}

1. Durand, G.A.; Raoult, D.; Dubourg, G. Antibiotic discovery: History, methods and perspectives. Int. J. Antimicrob. Agents 2019, 53, 371-382. [CrossRef] 
2. Rossiter, S.E.; Fletcher, M.H.; Wuest, W.M. Natural products as platforms to overcome antibiotic resistance. Chem. Rev. 2017, 117, 12415-12474. [CrossRef]

3. González, A.G.; Bazzocchi, I.L.; Moujir, L.M.; Jiménez, I.A. Ethnobotanical uses of Celastraceae. Bioactive metabolites. In Studies in Natural Products Chemistry: Bioactive Natural Products; (Part D); Atta-ur-Rahman, Ed.; Elsevier Science Publisher: Amsterdam, The Netherlands, 2000; Volume 23, pp. 649-738.

4. Niero, R.; de Andrade, S.F.; Cechinel, V.F. A review of the ethnopharmacology, phytochemistry and pharmacology of plants of the Maytenus genus. Curr. Pharm. Des. 2011, 17, 1851. [CrossRef]

5. Gunatilaka, A.A.L. Triterpenoid quinonemethides and related compounds (celastroloids). In Progress in the Chemistry of Organic Natural Products; Herz, W., Kirby, G.W., Moore, R.E., Steglich, W., Tamm, C., Eds.; Springer: New York, NY, USA, 1996; Volume 67, pp. 1-123.

6. Chen, S.-R.; Dai, Y.; Zhao, J.; Lin, L.; Wang, Y.; Wang, Y. A mechanistic overview of triptolide and celastrol, natural products from Tripterygium wilfordii Hook F. Front. Pharmacol. 2018, 9, 1-13. [CrossRef]

7. Yousef, B.A.; Hassan, H.M.; Zhang, L.-Y.; Jiang, Z.-Z. Anticancer potential and molecular targets of pristimerin: A mini review. Curr. Cancer Drug Targets 2017, 17, 100-108. [CrossRef]

8. Alvarenga, N.; Ferro, E.A. Bioactive triterpenes and related compounds from Celastraceae. In Studies in Natural Products Chemistry: Bioactive Natural Products; (Part K); Bioactive triterpenes and related compounds from Celastraceae; Atta-ur-Rahman, Ed.; Elsevier Science Publisher: Amsterdam, The Netherlands, 2006; Volume 33, pp. 239-307.

9. Bazzocchi, I.L.; Núñez, M.J.; Reyes, C.P. Diels-Alder adducts from Celastraceae species. Phytochem. Rev. 2018, 17, 669-690. [CrossRef]

10. Li, P.P.; He, W.; Yuan, P.F.; Song, S.S.; Lu, J.T.; Wei, W. Celastrol induces mitochondria-mediated apoptosis in hepatocellular carcinoma Bel-7402 cells. Am. J. Chin. Med. 2015, 43, 137-148. [CrossRef]

11. Rodrigues, A.C.B.C.; Oliveira, F.P.; Dias, R.B.; Sales, C.B.S.; Rocha, C.A.G.; Soares, M.B.P.; Costa, E.V.; Silva, F.M.A.; Rocha, W.C.; Koolen, H.H.F.; et al. In vitro and in vivo anti-leukemia activity of the stem bark of Salacia impressifolia (Miers) A. C. Smith (Celastraceae). J. Ethnopharmacol. 2019, 231, 516-524. [CrossRef]

12. Dai, W.; Wang, X.; Teng, H.; Li, C.; Wang, B.; Wang, J. Celastrol inhibits microglial pyroptosis and attenuates inflammatory reaction in acute spinal cord injury rats. Int. Immunopharmacol. 2019, 66, 215-223. [CrossRef]

13. Santos, V.A.F.F.M.; Santos, D.P.; Castro-Gamboa, I.; Zanoni, M.V.B.; Furlan, M. Evaluation of antioxidant capacity and synergistic associations of quinonemethide triterpenes and phenolic substances from Maytenus ilicifolia (Celastraceae). Molecules 2010, 15, 6956-6973.

14. Liao, L.M.; Silva, G.A.; Monteiro, M.R.; Albuquerque, S. Trypanocidal activity of quinonemethide triterpenoids from Cheiloclinium cognatum (Hippocrateaceae). Z. Naturforsch C 2008, 63, 207-210. [CrossRef]

15. Avilla, J.; Teixidó, A.; Velázquez, C.; Alvarenga, N.; Ferro, E.; Canela, R. Insecticidal activity of Maytenus species (Celastraceae) nortriterpene quinone methides against Codling Moth, Cydia pomonella (L.) (Lepidoptera: Tortricidae). J. Agric. Food Chem. 2000, 48, 88-92. [CrossRef]

16. Moujir, L.; Gutiérrez-Navarro, A.M.; González, A.G.; Ravelo, A.G.; Luis, J.G. The relationship between structure and antimicrobial activity in quinones from the Celastraceae. Biochem. Syst. Ecol. 1990, 18, 25-28. [CrossRef]

17. González, A.G.; Ravelo, A.G.; Bazzocchi, I.L.; Jiménes, J.; González, C.M.; Luis, J.G.; Ferro, E.A.; Gutiérrez, A.; Moujir, L. Biological study of triterpenoquinones from Celastraceae. Il Farmaco 1988, 43, 501-505.

18. Moujir, L.; Gutiérrez-Navarro, A.M.; González, A.G.; Ravelo, A.G.; Luis, J.G. Mode of action of netzahualcoyone. Antimicrob. Agents Chemother. 1991, 35, 211-213. [CrossRef]

19. Moujir, L.; Gutiérrez-Navarro, A.M.; González, A.G.; Ravelo, A.G.; Jiménez, J. Biological properties of netzahualcoyone: Conditions for activity. Biomed. Lett. 1991, 46, 7-15.

20. González, A.G.; Alvarenga, N.L.; Ravelo, A.G.; Jiménez, I.A.; Bazzocchi, I.L.; Canela, N.J.; Moujir, L. Antibiotic phenol nor-triterpenes from Maytenus canariensis. Phytochemistry 1996, 43, 129-132. [CrossRef]

21. Rodríguez, F.M.; López, M.R.; Jiménez, I.A.; Moujir, L.; Ravelo, A.G.; Bazzocchi, I.L. New phenolic triterpenes from Maytenus blepharodes.Semisynthesis of 6-deoxoblepharodol from pristimerin. Tetrahedron 2005, 61, 2513-2519. [CrossRef]

22. De León, L.; Beltrán, B.; Moujir, L. Antimicrobial activity of 6-oxophenolic triterpenoids. Mode of action against Bacillus subtilis. Planta Med. 2005, 71, 313-319. [CrossRef]

23. De León, L.; Moujir, L. Activity and mechanism of the action of zeylasterone against Bacillus subtilis. J. Appl. Microbiol. 2008, 104, 1266-1274. [CrossRef] 
24. De León, L.; López, M.R.; Moujir, L. Antibacterial properties of zeylasterone, a triterpenoid isolated from Maytenus blepharodes, against Staphylococcus aureus. Microbiol. Res. 2010, 165, 617-626. [CrossRef]

25. López, M.R.; de León, L.; Moujir, L. Antibacterial properties of phenolic triterpenoids against Staphylococcus epidermidis. Planta Med. 2011, 77, 726-729. [CrossRef]

26. Shirota, O.; Morita, H.; Takeya, K.; Itokawa, H. Cytotoxic aromatic triterpenes from Maytenus ilicifolia and Maytenus chuchuhuasca. J. Nat. Prod. 1994, 57, 1675-1681. [CrossRef]

27. González, A.G.; Alvarenga, N.L.; Rodríguez, F.; Ravelo, A.G.; Jiménez, I.A.; Bazzocchi, I.L.; Gupta, M.P. New phenolic and quinone-methide triterpenes from Maytenus species (Celastraceae). Nat. Prod. Lett. 1995, 7 , 209-218. [CrossRef]

28. Ankli, A.; Heilmann, J.; Heinrich, M.; Sticher, O. Cytotoxic cardenolides and antibacterial terpenoids from Crossopetalum gaumeri. Phytochemistry 2000, 54, 531-537. [CrossRef]

29. Gamlath, C.; Gunaherath, K.B.; Gunatilaka, A.A.L. Studies on terpenoids and steroids. Part 10. Structures of four new natural phenolic D:A-friedo-24-noroleanane triterpenoids. J. Chem. Soc. Perkin Trans. I 1987, 2849-2853. [CrossRef]

30. Kamal, G.M.; Gunaherath, K.B.; Gunatilaka, A.A.L. Studies on terpenoids and steroids. Part 10. Structures of four new natural phenolic D:A-friedo-24-noroleanane triterpenoids. J. Chem. Soc. Perkin Trans. I 1983, 2845-2850. [CrossRef]

31. Gunatilaka, A.A.L.; Wimalasiri, W.R. Studies on terpenoids and steroids. Part 22. Structure and some reactions of pristimerin leucotriacetate. J. Chem. Res. S 1992, 1, 30-31. [CrossRef]

32. CLSI. Methods for Dilution Antimicrobial Susceptibility test for Bacteria that Grow Aerobically, 9th ed.; Approved standard M07-A9; Clinical and Laboratory Standards: Wayne, PA, USA, 2012.

33. Barzic, A.I.; Ioan, S. Antibacterial drugs-From basic concepts to complex therapeutic mechanisms of polymer systems. In Concepts, Compounds and the Alternatives of Antibacterials; Bobbarala, V., Ed.; Science, Technology and Medicine: London, UK, 2015.

34. Software-Predicted Lipophilicity of the Compounds was Calculated with the ALOGPS 2.1 Program. Available online: www.vcclab.org/lab/alogps/accessibleviainterneton-lineLipophilicity/ AqueousSolubilityCalculationSoftware. (accessed on 20 May 2019).

(C) 2019 by the authors. Licensee MDPI, Basel, Switzerland. This article is an open access article distributed under the terms and conditions of the Creative Commons Attribution (CC BY) license (http://creativecommons.org/licenses/by/4.0/). 